\title{
Maternal perceptions about caesarean section deliveries and their role in reducing perinatal and neonatal mortality in the Upper West Region of Ghana; a cross- sectional study
}

Barnabas B. Naa Gandau ${ }^{1,2}$, Benjamin D. Nuertey ${ }^{3,4^{*}}$ (D) Nana Ayegua Hagan Seneadza ${ }^{3}$, Dominic Akaateba², Emmanuel Azusong ${ }^{2}$, Judith Y. Yirifere ${ }^{2}$, Herta B. Kankpeyeng ${ }^{5}$ and Edem M. A. Tette ${ }^{3}$

\begin{abstract}
Background: Maternal perceptions about caesarean section contribute to delayed presentation of women for emergency obstetric care. This increases the risks of perinatal and neonatal mortality and slows down the reductions needed to achieve the sustainable development goal (SDG) target of reducing neonatal mortality and ending new-born deaths. The aim of the study is to determine maternal perceptions about caesarean section deliveries and their role in reducing neonatal mortality at a regional and a district hospital in the Upper West Region of Ghana.

Methods: This descriptive study was carried out at two hospitals in the Upper West Region, the most rural region in Ghana, between 15th January and 29th June, 2018. Maternal perceptions were examined among antenatal care attendants at the Upper West Regional Hospital (UWRH) and St Joseph's Hospital Jirapa (SJH), a district hospital, using questionnaires administered by trained nurses.

Results: Altogether, 416 completed questionnaires were obtained, comprising 206 from expectant women attending the UWRH and 210 from $\mathrm{SJH}$. Although the majority of women in this study preferred spontaneous vaginal delivery $(87.4 \%, n=348)$ to caesarean section, most of the respondents $(n=281,73 \%)$ indicated their willingness to have a caesarean section if necessary. The main reason for not wanting a CS was the long recovery time $(51.8 \%, n=148)$. Almost half of women interviewed, representing $45.1 \%(180)$ did not know or feel that CS can promote child survival and about a fifth, 21.6\% (85) believed that CS can have adverse effects on child survival. Factors associated with poor perception of CS included, no formal education, age less than 19 years and no employment.

Conclusion: Majority of women in this study had a positive attitude towards the uptake of CS if it becomes necessary. Lack of formal education, age less than 19 years and unemployment are associated with poor maternal perception of CS. Education to improve the perception of CS as a promoter of child survival is necessary and to discourage perceptions that it causes adverse perinatal or neonatal outcome particularly in at risk populations.
\end{abstract}

Keywords: Caesarean section, Neonates, Maternal perceptions, SDG, Antenatal clinic

\footnotetext{
* Correspondence: ben.nuertey@gmail.com

${ }^{3}$ Community Health Department, School of Public Health, University of Ghana, Accra, Ghana

${ }^{4}$ Public Health Department, Tamale Teaching Hospital, Tamale, Ghana

Full list of author information is available at the end of the article
}

(c) The Author(s). 2019 Open Access This article is distributed under the terms of the Creative Commons Attribution 4.0 International License (http://creativecommons.org/licenses/by/4.0/), which permits unrestricted use, distribution, and reproduction in any medium, provided you give appropriate credit to the original author(s) and the source, provide a link to the Creative Commons license, and indicate if changes were made. The Creative Commons Public Domain Dedication waiver (http://creativecommons.org/publicdomain/zero/1.0/) applies to the data made available in this article, unless otherwise stated. 


\section{Background}

Neonatal and perinatal mortality in low and middle income countries is a matter of concern. This is because in the year 2015 alone, almost half ( 2.7 million) of the 5.9 million under-five deaths occurred during the neonatal period [1]. In addition, about $98 \%$ of global perinatal and neonatal mortalities are reported to occur in low and middle income countries [2]. In Ghana, for instance, the neonatal mortality rate in 2017 was estimated at 29 per 1000 live births $[3,4]$ and it represented $48 \%$ of under-five mortality (60/1000 live births). Meanwhile, the Sustainable Development Goals (SDGs) seek to tackle this problem with the aim of ending preventable deaths of new-borns and reducing neonatal mortality to at least as low as 12 deaths per 1000 live births by $2030[5,6]$.

It is estimated that, improved care at birth has the potential of preventing 1.3 million stillbirths within these regions by the year 2020, especially since the majority of the causes of stillbirths are preventable [7]. Therefore, since neonatal and perinatal deaths are closely related to the quality of care a woman receives during pregnancy and labour, accessibility of emergency obstetric care services including caesarean section when indicated is essential for reducing these deaths $[8,9]$.

Studies have shown that having a skilled attendant at delivery, and institutional delivery in general, has been associated with reductions in maternal, perinatal and neonatal mortality [10]. One of the critical advantages of institutional skilled delivery is the window of opportunity for surgical intervention when needed. Access to caesarean section is recognised as an essential component of obstetric care [11, 12] and, when medically justified, it is known to prevent perinatal and maternal morbidity and mortality [13]. However, maternal perceptions about caesarean section may influence the likelihood of mothers opting for institutional delivery which in turn affects access to this intervention, especially when it is most needed. It has been reported that caesarean section rates at population levels higher than $10 \%$ were not associated with reductions in maternal and newborn mortality rates $[14,15]$. However, in Africa where the median caesarean section rate is estimated to be $8.8 \%$, the risk of neonatal death is reported to be lower in settings having higher elective caesarean section rates [16]. The national average of caesarean section rates in Ghana is estimated at $12.8 \%$ but it ranges from 11.2-14.6 [17]; even then, there are wide disparities in access and uptake of caesarean section in urban and rural areas which may be partly related to perceptions about caesarean section.

There is a widespread belief that West African women have an aversion for surgical delivery and to have a CS is regarded as a reproductive failure [18-22]. Vaginal delivery is regarded as the ideal and a status symbol of womanhood; therefore, women who have had a CS might feel loss of the idealised birth they had hoped for, loss of part of their womanhood, and live in fear that other women may ridicule them [18-22]. A recent at study conducted in the Upper West Region described women's perception of caesarean section delivery as highly problematic; and that CS delivery acts as a long term disease [23]. This was because the respondents felt that having a CS incapacitated women for an extended period of time making them unable to fulfil domestic and economic roles which were inimical to the survival of their families. Such perceptions, when widespread, have the tendency of affecting the uptake of medically indicated caesarean sections aimed at preventing perinatal and neonatal mortality, especially among rural women. The aim of this study was to explore maternal perceptions about caesarean section deliveries, and their role in reducing perinatal and neonatal mortality among antenatal attendants in selected hospitals in the Upper West Region of Ghana.

\section{Methods \\ Study sites}

The study took place at two sites within the Upper West Region: the Upper West Regional Hospital (UWRH) that is located at $\mathrm{Wa}$, the regional capital which is predominantly urban, and the St. Joseph's Hospital in the Jirapa District, which is more rural. The UWRH currently serves as a municipal and regional hospital. It is, however, the main referral centre within the healthcare delivery system in the Upper West Region, which shares a border with Burkina Faso and Cote d'Ivoire. The hospital currently has a bed capacity of 200, spread over 9 wards. The hospital's neonatal intensive care unit (NICU) became functional at the latter part of 2016 and the hospital had a total delivery of 4915 in 2016 and 4969 in 2017. Anecdotal evidence suggests that prior to this, there had been rumours among the mothers that delivery by CS in the UWRH hospital was likely to be associated with poor maternal and neonatal outcomes. This study provides an opportunity to determine whether this prevails.

St. Joseph's Hospital (SJH) assumes the role of a district hospital for the Jirapa District. It has seven (7) wards and this include a neonatal intensive care unit (NICU), which started operations in 2015 and was the first to be established in the Upper West Region. The total deliveries for the year 2016 were 1709 and 1663in 2017.

\section{Study design}

This study was a cross-sectional study involving pregnant women attending antenatal clinics in two hospitals within the Upper West Region (UWR) and was conducted from $15^{\text {th }}$ January 2018 to 29 th June, 2018. It was a questionnairebased study which examined the perceptions and experiences of pregnant women with caesarean section and the role that these perceptions and experiences play in reducing 
perinatal and neonatal mortality. The questionnaires were administered by trained nurses at the antenatal clinic.

\section{Study population}

Expectant mothers were the participants in this study. All women attending antenatal clinics in the UWRH and the $\mathrm{SJH}$ hospitals were eligible for inclusion into the study. Pregnant women who were ill and in pain, as well as pregnant women who did not give consent were excluded from the study.

\section{Sampling technique and sample size}

The sample size for the study was based on the assumption that the proportion of expectant mothers attending the ANC with good knowledge about caesarean section (p) is $50 \%(0.5)$. Thus at a desired confidence interval of $95 \%$ and an allowable error of $5 \%$, a minimum sample size of 384 pregnant women attending the antenatal clinic was required. For the purpose of this study, we aimed at recruiting at least 200 participants from each study site. Using systematic sampling with antenatal registers as the sampling frame, we estimated an average of five questionnaires to be administered per day per study site within the 2 month of data collection until the desired sample size is reached. This was based on the assumption that since antenatal clinics are held on week days, 5 questionnaires a day will give us 25 in a week and 100 in a month, So that in 2 months we would obtain 200 questionnaires from each site but unfortunately the data collection took longer than we anticipated which is partly been due to cancelled clinic and holidays.

\section{Data collection procedure and study instrument}

A structured questionnaire consisting of both closed and open-ended questions was used to assess antenatal attendants' experiences, knowledge and perceptions towards Caesarean section (CS) delivery. The questionnaire included questions on socio-demographic information such as age, marital status, occupation, religion, ethnicity and level of education. A brief obstetric history provided information on parity, number of stillbirths or pregnancies lost and the reason for the losses. The knowledge and attitude of respondents to CS was assessed based on respondents' response to questions such as whether they had heard about CS, reasons why some women have CS, complications of the procedure, how long someone stays in the hospital after a CS, whether blood transfusion may be required during the procedure, and whether a pregnant woman can opt for CS without medical indications. The questionnaire is attached as additional file 1 . The questionnaires were pretested at the Wechiau District Hospital, which is also in the Upper West Region, before use.

\section{Ethical considerations}

Permission to carry out this research was obtained from the Medical Directors of the Regional Hospital and St Joseph's District Hospital. Ethical Approval was obtained from the Ghana Health Service Ethical Review Committee (GHS-ERC: 09/03/17). Written informed consent was obtained from each study participant before the administration of questionnaires. Assent was obtained from all participants less than 16 years and consent obtained from their legal guardian/parent. In carrying out the interviews, privacy and confidentiality were ensured. Participation was based entirely on goodwill and there was no compensation for participating in this study.

\section{Data management and analysis}

A unique study number was assigned to each participant and used for the storage and management of all data relating to that patient. The data were captured using Statistical Package for Social Sciences (SPSS) version 16.0. Cleaning of data was done using standardised queries to conduct range and logic check. Discrepant entries were rectified by reviewing the record form. The data was exported into STATA version 11 (StataCorp, Texas, USA). The results were expressed as means and standard deviations (SD) for continuous variables and percentages for categorical variables such as age and sex. Statistical significance was accepted at a $5 \%$ probability level, that is, a $p$-value of less than 0.05 . Cross tabulations and multiple response analysis were carried out where necessary. Logistic regression was also carried out to determine factors associated with poor perception of caesarean section among women attending the antenatal clinic.

\section{Results}

Altogether 416 pregnant women took part in the study. Response rates observed in the study was $98 \%$. In all, $50.5 \%(n=210)$ of the expectant mothers attended antenatal clinic at St Joseph's hospital, Jirapa, while 49.5\% $(n=206)$ attended at the Upper West Regional Hospital. The age range of study participants was from 14 to 45 years with a mean age of $27(S D=6.0)$ years. Table 1 displays the background characteristics of study participants from the two study sites. With regard to the obstetric history, the current pregnancy bringing them to ANC ranged between the first to the ninth for study participants. About a third of study participants $34.2 \%$ $(n=142)$, had lost a pregnancy or had had a perinatal mortality. Among those who had had a perinatal mortality, the number of stillbirths ranged from one to a maximum of four. Table 2 displays the obstetric history of study participants and reasons ascribed for the causes of pregnancy loss or stillbirth varied. In all, $34.6 \%$ had no knowledge of the cause. 
Table 1 Background characteristics of study participants by study site

\begin{tabular}{|c|c|c|c|c|}
\hline \multirow{3}{*}{ Maternal Characteristics } & \multicolumn{2}{|l|}{ Hospital Attended } & \multirow{3}{*}{$\begin{array}{l}\text { Total } \\
\text { N (\%) }\end{array}$} & \multirow{3}{*}{$P$-Value } \\
\hline & Upper West Regional Hospital & St Joseph's Hospital & & \\
\hline & N (\%) & N (\%) & & \\
\hline Number of Antenatal patients & $206(49.5)$ & $210(50.5)$ & $416(100)$ & \\
\hline Age of Pregnant woman in years & & & & 0.831 \\
\hline 19 and below & $27(13.1)$ & $22(10.5)$ & 49 (11.8) & \\
\hline $20-24$ & $45(21.8)$ & $43(20.5)$ & $88(21.2)$ & \\
\hline $25-29$ & 65 (31.6) & $68(32.4)$ & $133(32.0)$ & \\
\hline $30-34$ & $42(20.4)$ & $51(24.3)$ & $93(22.4)$ & \\
\hline 35 and above & $27(13.1)$ & $26(12.4)$ & $53(12.7)$ & \\
\hline Highest Level of formal Education & & & & 0.001 \\
\hline No formal Education & $21(10.2)$ & $53,925.6)$ & $74(18.0)$ & \\
\hline Primary School & $18(8.8)$ & $30(14.5)$ & $48(11.6)$ & \\
\hline Junior Secondary School & $12(5.9)$ & $37(17.9)$ & $49(11.9)$ & \\
\hline Senior Secondary School & $40(19.5)$ & $23(11.1)$ & $63(15.3)$ & \\
\hline Vocational / Technical & $24(11.7)$ & $4(1.9)$ & $28(6.8)$ & \\
\hline Tertiary & $90(43.9)$ & $59(28.0)$ & $148(35.9)$ & \\
\hline Occupation & & & & 0.004 \\
\hline Unemployed & $43(20.9)$ & $43(20.7)$ & $86(20.7)$ & \\
\hline Trader & $32(15.5)$ & $21(10.1)$ & $53(12.8)$ & \\
\hline Artisan & $31(15.1)$ & $36(17.3)$ & $67(16.2)$ & \\
\hline Professional & $80(38.8)$ & $52(25.0)$ & $132(31.9)$ & \\
\hline Student & $13(6.3)$ & $24(11.5)$ & $37(8.9)$ & \\
\hline Other & $7(3.4)$ & $32(15.4)$ & $39(9.4)$ & \\
\hline Religion & & & & 0.001 \\
\hline Christianity & $119(57.8)$ & $180(86.5)$ & $299(72.2)$ & \\
\hline Islam & $84(40.8)$ & $13(6.3)$ & $97(23.4)$ & \\
\hline Traditional & $3(1.5)$ & 14 96.7) & $17(4.1)$ & \\
\hline Others & - & $1(0.5)$ & $1(0.2)$ & \\
\hline Marital Status & & & & 0.001 \\
\hline Never Married & $37(18.5)$ & $7(3.4)$ & $44(10.8)$ & \\
\hline Currently Married & $106(53.0)$ & $188(90.8)$ & $294(72.2)$ & \\
\hline Co-habiting & $48(24.0)$ & $11(5.3)$ & $59(14.5)$ & \\
\hline Widowed & $4(2.0)$ & $1(0.5)$ & $5(1.2)$ & \\
\hline Separated & $5(2.5)$ & - & $5(1.2)$ & \\
\hline Ethnicity & & & & 0.001 \\
\hline Akan & $24(11.8)$ & $10(4.8)$ & $34(8.2)$ & \\
\hline Ga/ Dangme & $8(3.9)$ & $1(0.5)$ & $9(2.2)$ & \\
\hline Ewe & $16(7.8)$ & - & $16(3.9)$ & \\
\hline Northern ethnic groups & $149(73.0)$ & $196(93.3)$ & $345(83.3)$ & \\
\hline Non-Ghanaians & $7(3.4)$ & $1(0.5)$ & $8(1.9)$ & \\
\hline Others & - & $2(1.0)$ & $2(0.5)$ & \\
\hline
\end{tabular}


Table 2 Maternal Obstetric history

\begin{tabular}{|c|c|c|c|c|}
\hline \multirow[t]{2}{*}{ Maternal Characteristics } & Upper West Regional Hospital & St Joseph's Hospital & Total & \multirow[t]{2}{*}{$P$-Value } \\
\hline & N (\%) & N (\%) & N (\%) & \\
\hline $\begin{array}{l}\text { Number of times } \\
\text { pregnant (gravidity) }\end{array}$ & & & & 0.285 \\
\hline First pregnancy & $64(31.1)$ & $67(31.9)$ & $131(31.5)$ & \\
\hline Second & $46(22.3)$ & $64(30.5)$ & $110(26.4)$ & \\
\hline Third & $37(18.0)$ & $27(12.9)$ & $64(15.4)$ & \\
\hline Fourth & $34(16.5)$ & $31(14.8)$ & 65 (15.6) & \\
\hline Fifth and above & $25(12.1)$ & $21(10.00$ & $46(11.1)$ & \\
\hline Number of children (Parity) & & & & 0.001 \\
\hline None & $82(39.8)$ & $10(5.2)$ & $92(23.8)$ & \\
\hline One & $50(24.3)$ & $77(42.5)$ & $127(32.8)$ & \\
\hline Two & $47(22.8)$ & $46(25.4)$ & $93(24.0)$ & \\
\hline Three & $18(8.7)$ & $25(13.8)$ & $43(11.1)$ & \\
\hline Four and above & $9(4.4)$ & $23(12.7)$ & $32(8.3)$ & \\
\hline History of Lost pregnancy/ Stillbirth & & & & 0.001 \\
\hline Yes & $96(46.6)$ & $46(22.0)$ & $142(34.2)$ & \\
\hline No & $110(53.4)$ & $163(78.0)$ & $273(65.8)$ & \\
\hline $\begin{array}{l}\text { Number of Lost } \\
\text { pregnancy/Stillbirths }\end{array}$ & & & & 0.041 \\
\hline One & $62(66.0)$ & $38(86.4)$ & $100(72.5)$ & \\
\hline Two & $24(25.5)$ & $5(11.4)$ & $29(21.0)$ & \\
\hline Three and above & $8(8.5)$ & $1(2.3)$ & $8(5.8)$ & \\
\hline $\begin{array}{l}\text { Causes of the pregnancy loss } \\
\text { (multiple response analysis) }\end{array}$ & & & & 0.001 \\
\hline Do not know & $22(23.9)$ & $25(56.8)$ & $47(34.6)$ & \\
\hline Infection & $5(5.4)$ & $5(5.4)$ & $10(7.4)$ & \\
\hline Stress & $5(5.4)$ & $5(11.4)$ & $10(7.4)$ & \\
\hline Hypertension in pregnancy & - & $3(6.8)$ & $3(2.2)$ & \\
\hline Diabetes in pregnancy & - & $1(2.3)$ & $1(0.7)$ & \\
\hline Malaria in pregnancy & $2(2.2)$ & $2(4.6)$ & $4(2.9)$ & \\
\hline Spontaneous Abortion & $30(32.6)$ & 5911.4) & $41(30.2)$ & \\
\hline Induced Abortion & $31(33.7)$ & $5(11.4)$ & $36(26.4)$ & \\
\hline Other reasons & $11(12.0)$ & $1(2.3)$ & $12(8.8)$ & \\
\hline
\end{tabular}

\section{Experience with caesarean section}

A total number of 96 respondents (representing 26\%) had had a previous history of Caesarean section. Table 3 displays the experiences of ANC attendants with caesarean section. The proportion of ANC attendants who had had caesarean section was higher among those attending ANC in the district hospital at $38.4 \%(n=66)$ compared to those attending ANC in the regional hospital, which was at $15.7 \%(n=30)$. The majority of women stated that, the indication for the previous caesarean section was "big baby', accounting for $42.1 \%$ of the indication for caesarean section. Other reasons for the caesarean section included previous caesarean section, $26.1 \%(n=23)$, baby not lying well, $25.0 \%(n=22)$, and antepartum haemorrhage $4.6 \%(n=4)$. Maternal request was the least, accounting for $1.1 \%(n=1)$.

With regard to the overall description of the caesarean section experience, $66.3 \%(n=57)$ of participants who had a previous caesarean section described it as painful while a total of $14.0 \%(n=12)$ described it as good. There was no statistical difference between the experiences of respondents who had their caesarean section at the district hospital and those who had theirs at the regional hospital $(p=0.267)$. In all, $28.1 \%(n=25)$ of the pregnant women who had a previous history caesarean section wished they had information on the complications of the surgery prior to the surgery. 
Table 3 Maternal experience with caesarean section

\begin{tabular}{ll}
\hline Maternal Characteristics & Upper West Regional Hospital \\
& $\mathrm{N}(\%)$ \\
\hline History of Previous caesarean section & $30(15.7)$ \\
Had a previous caesarean section & $161(84.3)$ \\
No previous caesarean section & \\
Indication for previous caesarean & \\
section (multiple response analysis) & $24(41.4)$ \\
Big baby & $23(39.7)$ \\
Previous Caesarean section & $7(12.1)$ \\
Baby not lying well & $4(6.0)$ \\
Bleeding (Antepartum Haemorrhage) & $10(17.2)$ \\
Repeated Miscarriages & $1(1.7)$ \\
Complicated Hypertension in pregnancy & - \\
Maternal request & - \\
Not told the reason for Caesarean section & $6(10.3)$ \\
Others &
\end{tabular}

\begin{tabular}{lll} 
St Joseph's Hospital & Total & $P$-values \\
N (\%) & $N(\%)$ & \\
\hline
\end{tabular}

$66(38.4)$

$96(26.5)$

$106(61.6)$

$267(73.6)$

Overall description of Caesarean section experience (multiple response analysis)

$\begin{array}{ll}\text { Good } & 8(13.6) \\ \text { Painful } & 39(66.1) \\ \text { Long stay in Hospital } & 22(37.3) \\ \text { Bad attitude of Staff } & 6(10.2) \\ \text { Others } & 3(5.1)\end{array}$

Information wished to have known

(multiple response analysis)

\section{Reason for having the caesarean section \\ Complications of the surgery \\ Duration of stay in hospital \\ Cost of the caesarean section \\ Effects of medications on baby}

Other questions on caesarean section

What would have made your caesarean section (CS) experience better (Multiple response analysis)

Education on CS at antenatal clinic
Better staff attitude
Shorter stay at hospital
Been told earlier about having CS

Experienced complication of

Caesarean section (Multiple

response analysis)

$\begin{array}{ll}\text { Bleeding } & 11(18.3) \\ \text { Infection of wound } & 4(6.7) \\ \text { Sick baby } & 6(10) \\ \text { Reaction to anaesthesia medications } & - \\ \text { No complications } & 34(56.7) \\ \text { Other complications } & 8(13.3)\end{array}$

Form of Anaesthesia

used for surgery

$3(5.0)$

$8(13.3)$

$13(21.7)$

$6(10.0)$

$3(5.0)$

$36(60.0)$

$37(75.5)$

9 (18.4)

$4(8.2)$

8 (16.3)

$8(13.3)$

$54(91.5)$
$37(42.1)$

$-$

$15(50.0)$

$23(26.1)$

$22(25.0)$

4 (4.6)

$-$

$10(11.4)$

$2(6.7)$

$3(3.4)$

1 (3.3)

$1(1.1)$

$2(6.7)$

$2(2.3)$

$5(16.7)$

$11(12.5)$
17 (58.6)

17 (58.6)

7 (24.1)

4 (13.8)

2 (6.9)

2 (6.9)

$20(71.4)$

57 (74.0)

5 (17.9)

14 (18.2)

5 (6.5)

$20(26.0)$

20 (22.5)

25 (28.1)

20 (22.5)

$10(11.2)$

5 (5.6)

38 (42.7)
0.001

0.207

0.001

0.267

0.059

$\begin{array}{ll}1(3.3) & 12(13.3) \\ 2(6.7) & 6(6.7) \\ - & 6(6.7) \\ 1(3.3) & 1(1.1) \\ 26(86.7) & 60(66.7) \\ 3(10.0) & 11(12.2)\end{array}$


Table 3 Maternal experience with caesarean section (Continued)

\begin{tabular}{llll}
\hline Maternal Characteristics & Upper West Regional Hospital & St Joseph's Hospital & Total \\
& $\mathrm{N}(\%)$ & $\mathrm{N}(\%)$ & $\mathrm{N}(\%)$ \\
\hline General & $5(8.5)$ & $7(23.3)$ & $12(13.5)$ \\
$\begin{array}{l}\text { Procedure explained } \\
\text { before caesarean section }\end{array}$ & & & 0.001 \\
Procedure explained & $55(98.2)$ & $21(72.4)$ & $76(89.4)$ \\
Procedure not explained & $1(1.8)$ & $8(27.6)$ & $9(10.6)$ \\
\hline
\end{tabular}

\section{Knowledge and perception of women attending antenatal clinic on caesarean section}

Table 4 displays the results of the knowledge and perception of women attending ANC on caesarean section. Altogether, 364 (91\%) women had heard about caesarean section. Pregnant women who had heard about caesarean section reported several reasons why women have caesarean section and these reasons are summarised in Table 4. Vaginal birth after caesarean section (VBAC) was acknowledged as possible by $77.7 \%(n=313)$ of the respondents, whereas $4.5 \%(n=18)$ believed that women can no longer have a vaginal delivery after a caesarean section and $17.9 \%(n=72)$ stated that they had no idea about the possibility of vaginal birth after a previous caesarean section. The majority of the women interviewed preferred planned spontaneous vaginal delivery $(87.4 \%, n=348)$ to caesarean section though a small proportion, $3.9 \%(n=42)$ of them preferred caesarean section to spontaneous vaginal delivery. A higher proportion of women with a previous caesarean section $(34.5 \%, n=30)$ preferred CS delivery compared to women without prior CS $(3.9 \%, n=$ 12). In all $8.6 \%$ of all participants said they were unwilling to have caesarean section even if necessary.

With regard to the effect of CS on child survival, $55.1 \%$ $(n=217)$ stated that CS has no effect on their child's survival. However, $21.6 \%(n=85)$ and $23.4 \%(n=92)$ of women respectively stated that " $C S$ can have adverse effect on child survival" and "I don't know the effect of CS on child survival". Likewise $54.9 \%(n=219)$ perceived that CS can promote child survival while $12.3 \%(n=49)$ stated that CS does not promote child survival. Among those women who had previous caesarean section, 6.7\% (6/90) reported sick baby as complications to CS. Also, $28.7 \%$ $(112 / 403)$ of all pregnant women in the study believed that CS causes injury to baby.

Factors associated with poor perception of caesarean section among women attending ANC.

Tables 5 and 6 display the factors associated with poor perception of caesarean section among women. Pregnant women aged 19 years and below are more likely to have poor perception of caesarean section $(\mathrm{OR}=2.5,95 \% \mathrm{CI}$ $=1.0-6.5$ ) when compared to those aged 35 years and above. Highest educational status significantly affected perception of caesarean section among pregnant women attending ANC. Compared with pregnant women who completed a tertiary education, having no formal education was $2.2(95 \% \mathrm{CI}=1.2-4.1)$ times more likely to be associated with poor perception of CS. With regard to occupational status, the professionals were less likely to have poor perception of CS when compared to the unemployed $(\mathrm{OR}=0.4,95 \% \mathrm{CI}=0.2-0.7)$.

Pregnant women who were undecided or unwilling to undergo caesarean section were 4.4 times $(95 \% \mathrm{CI}=2.4-$ 8.3) more likely have poor perception about caesarean section. Also pregnant women who preferred planned spontaneous vaginal delivery compared to CS were 7.3 (95\% CI $=3.7-14.4)$ times more likely to have poor perception of CS. Other factors that were independently associated with the poor perception of caesarean section included the following: no previous caesarean section history $(\mathrm{OR}=3.5,95 \% \mathrm{CI}=2.1-5.7)$. In a model adjusting for maternal age, educational status and religion, the following factors remain significantly associated with poor perception of caesarean section: undecided or not willing to undergo caesarean section $(\mathrm{OR}=3.8,95 \% \mathrm{CI}=$ 2.0-7.3), preference for spontaneous vaginal delivery compared to planned caesarean section $(\mathrm{OR}=6.3,95 \%$ $\mathrm{CI}=3.0-13.4)$, attending $\mathrm{ANC}$ in a regional hospital $(\mathrm{OR}=3.0,95 \% \mathrm{CI}=1.7-5.2)$, having no history of a previous caesarean section $(\mathrm{OR}=2.4,95 \% \mathrm{CI}=1.4-4.1)$, and having vaginal delivery as the preferred mode of delivery $(\mathrm{OR}=3.0,95 \% \mathrm{CI}=1.3-6.7)$.

Factors associated with pregnancy loss/ perinatal mortality among women attending ANC.

Table 7 displays factors associated with perinatal mortality among women attending ANC. Comparing those with a history of caesarean section with women without history of CS, positive CS history was 4.6 times (95\% CI 2.7-7.8) more likely to be associated with likelihood of having a history of pregnancy loss or perinatal mortality. Also adjusting for educational status and religion, women having a traditional or religious belief against CS were 3.2 (1.3-7.9) times more likely to have a pregnancy/ perinatal mortality compared with pregnant women without such belief. Women attending ANC in the district hospital were less likely to have had a pregnancy loss or perinatal mortality compared with women attending ANC in the regional hospital (AOR $=0.4,95 \%$ CI 0.2-0.6). 
Table 4 Knowledge and Perception of pregnant women attending antenatal clinic on caesarean section

\begin{tabular}{|c|c|c|c|c|}
\hline \multirow{3}{*}{ Maternal knowledge and perception } & \multicolumn{3}{|c|}{ Previous caesarean section (CS) } & \multirow{3}{*}{$P$-Value } \\
\hline & Had a Previous CS & No history of CS & Total & \\
\hline & N (\%) & N (\%) & N (\%) & \\
\hline Study participants & $89(22.0)$ & $315(78.0)$ & $404(100.0)$ & \\
\hline Heard of caesarean section & & & & 0.001 \\
\hline Heard of caesarean section & $88(100.0)$ & $279(89.0)$ & $364(91.5)$ & \\
\hline Never heard of caesarean section & - & $34(11.0)$ & $34(8.4)$ & \\
\hline $\begin{array}{l}\text { Knowledge on why women } \\
\text { have caesarean section* }\end{array}$ & & & & 0.001 \\
\hline Big baby & $57(64.8)$ & $118(69.6)$ & $245(68.4)$ & \\
\hline Previous caesarean section & $27(30.7)$ & $69(25.6)$ & $96(26.8)$ & \\
\hline Baby not lying well & $37(42.1)$ & $130(48.2)$ & $167(46.7)$ & \\
\hline Baby in distress & $24(27.3)$ & $73(27.0)$ & $97(27.1)$ & \\
\hline Bleeding & $7(8.0)$ & $28(10.4)$ & $35(9.8)$ & \\
\hline Repeated miscarriages & $10(11.4)$ & $11(4.1)$ & $21(5.9)$ & \\
\hline Complications of hypertension in pregnancy & $11(12.5)$ & $31(11.5)$ & $42(11.7)$ & \\
\hline Complications of Diabetes in pregnancy & $8(9.1)$ & $25(9.3)$ & $33(9.2)$ & \\
\hline Request of mother & $10(11.4)$ & $74(27.4)$ & $84(23.5)$ & \\
\hline Other reasons & 19 (21.6) & $56(20.7)$ & $75(21.0)$ & \\
\hline $\begin{array}{l}\text { Can a woman give birth vaginally } \\
\text { after caesarean section }\end{array}$ & & & & 0.003 \\
\hline Can give birth vaginally & $80(89.9)$ & $233(74.2)$ & $313(77.7)$ & \\
\hline Cannot give birth vaginally & $4(4.5)$ & $14(4.5)$ & $18(4.5)$ & \\
\hline I don't know & $5(5.6)$ & $67(21.3)$ & $72(17.9)$ & \\
\hline $\begin{array}{l}\text { Is there a need for client education on } \\
\text { Caesarean section at antenatal clinic }\end{array}$ & & & & 0.001 \\
\hline There is a need & $86(96.3)$ & $247(79.4)$ & $333(83.4)$ & \\
\hline There is no need & $3(3.4)$ & $64(20.6)$ & $67(16.8)$ & \\
\hline $\begin{array}{l}\text { Preference of planned caesarean } \\
\text { section versus vaginal delivery }\end{array}$ & & & & 0.001 \\
\hline Caesarean section & $30(34.5)$ & $12(3.9)$ & $42(3.9)$ & \\
\hline Vaginal delivery & $53(60.9)$ & $295(94.9)$ & $348(87.4)$ & \\
\hline I don't know & $4(4.6)$ & $4(1.3)$ & $8(2.0)$ & \\
\hline $\begin{array}{l}\text { Willingness to undergo } \\
\text { caesarean section if the need be }\end{array}$ & & & & 0.001 \\
\hline Would undergo caesarean section & $76(93.8)$ & $205(67.4)$ & $281(73.0)$ & \\
\hline Would not undergo caesarean section & $2(2.5)$ & $31(10.2)$ & $33(8.6)$ & \\
\hline Undecided & $3(3.7)$ & $68(22.37)$ & $72(18.4)$ & \\
\hline $\begin{array}{l}\text { Reasons for not wanting } \\
\text { to have caesarean section* }\end{array}$ & & & & 0.997 \\
\hline Fear of been mocked & $1(2.0)$ & $21(8.9)$ & $22(7.7)$ & \\
\hline Fear of pain during and after surgery & $21(41.2)$ & $114(48.5)$ & $135(47.2)$ & \\
\hline Expensive & $3(5.9)$ & $22(9.4)$ & $25(8.7)$ & \\
\hline Long recovery time & $31(60.8)$ & $117(49.8)$ & $148(51.8)$ & \\
\hline To avoid getting a scar & $1(2.0)$ & 25 (10.6) & $26(9.1)$ & \\
\hline It prevents bonding with baby & - & $6(2.6)$ & $6(2.1)$ & \\
\hline Not natural & $7(13.7)$ & $66(28.1)$ & $73(25.5)$ & \\
\hline
\end{tabular}


Table 4 Knowledge and Perception of pregnant women attending antenatal clinic on caesarean section (Continued)

\begin{tabular}{|c|c|c|c|c|}
\hline \multirow{3}{*}{ Maternal knowledge and perception } & \multicolumn{3}{|c|}{ Previous caesarean section (CS) } & \multirow{3}{*}{ P-Value } \\
\hline & Had a Previous CS & No history of CS & Total & \\
\hline & $N(\%)$ & N (\%) & N (\%) & \\
\hline Not God's wish & - & 20 98.5) & $20(7.0)$ & \\
\hline Blood may be given in the process & - & $25(10.6)$ & $25(8.7)$ & \\
\hline May not see my baby & $1(2.0)$ & $5(2.1)$ & $6(3.1)$ & \\
\hline Fear of complications & $19(37.3)$ & $86(36.6)$ & $105(36.7)$ & \\
\hline \multicolumn{4}{|l|}{$\begin{array}{l}\text { How do you see a woman } \\
\text { who delivered by caesarean section }\end{array}$} & 0.001 \\
\hline Normal & $47(55.3)$ & $80(26.0)$ & $127(32.3)$ & \\
\hline Weak & $14(16.5)$ & $143(46.4)$ & $157(40.0)$ & \\
\hline Feel sorry for her & $12(14.1)$ & $73(23.7)$ & $85(21.6)$ & \\
\hline God's wish & $12(14.1)$ & $12(3.9)$ & $24(6.1)$ & \\
\hline \multicolumn{4}{|l|}{$\begin{array}{l}\text { Would you like to have caesarean } \\
\text { section (CS) for the following reasons }\end{array}$} & 0.001 \\
\hline CS delivery is less embarrassing & $25(49.0)$ & $65(50.8)$ & $90(50.3)$ & \\
\hline CS allows to choose the day of birth & $16(31.4)$ & $99(77.3)$ & $115(64.3)$ & \\
\hline Woman's body recovers faster with CS & - & $18(14.1)$ & $18(10.1)$ & \\
\hline Cs delivery is more convenient & $28(54.9)$ & $17(13.3)$ & $45(25.1)$ & \\
\hline \multicolumn{4}{|l|}{$\begin{array}{l}\text { Is there any traditional or cultural belief } \\
\text { that affects your preferred choice of delivery? }\end{array}$} & 0.001 \\
\hline There is a traditional or cultural belief & $14(15.9)$ & $10(3.3)$ & $24(6.1)$ & \\
\hline There is no traditional or cultural belief & $74(84.1)$ & $297(96.7)$ & $371(93.9)$ & \\
\hline \multicolumn{4}{|c|}{ Factors influencing your choice of place of delivery* } & 0.009 \\
\hline Place where I attend antenatal clinic & $47(52.8)$ & $106(34.1)$ & $153(38.3)$ & \\
\hline Skills of health workers & $66(74.2)$ & $193(62.1)$ & $259(64.8)$ & \\
\hline Know a staff member at the health facility & $2(2.3)$ & $8(2.6)$ & $10(2.5)$ & \\
\hline Proximity to where I live & $8(9.0)$ & $41(13.2)$ & $49(12.3)$ & \\
\hline Other reasons & $6(6.7)$ & $36(11.6)$ & $42(10.5)$ & \\
\hline \multicolumn{4}{|l|}{ Is there any facility you would like to avoid } & 0.001 \\
\hline There are facilities I would avoid & $26(29.2)$ & $21(6.8)$ & $47(11.8)$ & \\
\hline No facility that I would avoid & $63(70.1)$ & $290(93.3)$ & $353(88.4)$ & \\
\hline \multicolumn{4}{|c|}{ Can having caesarean section (CS) adversely affect your child } & 0.239 \\
\hline CS can adversely affect my child & $16(18.0)$ & $69(22.6)$ & $85(21.6)$ & \\
\hline CS has no effect on my child & $56(62.9)$ & $161(52.8)$ & $217(55.1)$ & \\
\hline Don't know & $17(19.1)$ & $75(24.6)$ & $92(23.4)$ & \\
\hline \multicolumn{4}{|c|}{ Can having caesarean (CS) section promote child survival } & 0.001 \\
\hline CS promote child survival & $73(82.0)$ & $146(47.1)$ & $219(54.9)$ & \\
\hline CS does not promote child survival & $6(6.7)$ & $43(13.9)$ & $49(12.3)$ & \\
\hline I don't know & $10(11.2)$ & $121(39.0)$ & $131(32.8)$ & \\
\hline
\end{tabular}

*multiple response analysis

\section{Discussion}

Globally, caesarean section rates increase with increasing socio-economic development and are a proxy measure for assessing progress in maternal and infant health [24, 25]. Thus one would have expected that the CS rate would be higher among women attending $\mathrm{ANC}$ at the regional hospital as has been reported at the Korle $\mathrm{Bu}$ Teaching Hospital [18]. However in this study, the proportion of ANC attendants with CS experience from the district hospital was more than twice the proportion of CS experience in the regional hospital. Data from this study showed that participants in the district hospital had a greater number 
Table 5 Crude odds ratio of factors associated with poor perception of caesarean section among pregnant women attending antenatal clinic

\begin{tabular}{|c|c|c|c|}
\hline Maternal characteristics & Crude Odds Ratio & 95\% Confidence interval & $P$-Value \\
\hline \multicolumn{4}{|l|}{ Age of Pregnant woman in years } \\
\hline 19 and below & 2.5 & $1.0-6.5$ & 0.06 \\
\hline $20-24$ & 1.5 & $0.7-3.1$ & 0.3 \\
\hline $25-29$ & 1.1 & $0.5-2.1$ & 0.8 \\
\hline $30-34$ & 0.6 & $0.3-1.3$ & 0.2 \\
\hline 35 and above & - & & \\
\hline \multicolumn{4}{|l|}{ Highest Level of formal Education } \\
\hline No formal Education & 2.2 & $1.2-4.1$ & 0.01 \\
\hline Primary School & 2.7 & $1.3-5.7$ & 0.01 \\
\hline Junior Secondary School & 3.0 & $1.4-6.7$ & 0.004 \\
\hline Senior Secondary School & 2.3 & $1.2-4.4$ & 0.01 \\
\hline Vocational / Technical & 1.9 & $0.8-4.6$ & 0.2 \\
\hline Tertiary & - & & \\
\hline \multicolumn{4}{|l|}{ Occupation } \\
\hline Unemployed & - & & \\
\hline Professional & 0.4 & $0.2-0.7$ & 0.002 \\
\hline Others example: artisans, traders etc & 0.7 & $0.4-1.2$ & 0.2 \\
\hline \multicolumn{4}{|l|}{ Number of children (Parity) } \\
\hline None & - & & \\
\hline One & 0.4 & $0.2-0.7$ & 0.002 \\
\hline Two & 0.4 & $0.2-0.8$ & 0.01 \\
\hline Three & 0.3 & $0.2-0.8$ & 0.01 \\
\hline Four and above & 1.0 & $0.4-2.8$ & 0.9 \\
\hline \multicolumn{4}{|l|}{ Willingness to undergo CS if the need be } \\
\hline Yes & - & & \\
\hline No or undecided & 4.4 & $2.4-8.3$ & 0.0001 \\
\hline \multicolumn{4}{|l|}{$\begin{array}{l}\text { Is there any facility you would } \\
\text { avoid for child delivery }\end{array}$} \\
\hline No & - & & \\
\hline Yes & 0.3 & $0.2-0.60$ & 0.0003 \\
\hline \multicolumn{4}{|l|}{$\begin{array}{l}\text { Having traditional or cultural belief } \\
\text { on choice of delivery method }\end{array}$} \\
\hline No traditional or cultural belief & - & & \\
\hline Have a traditional or cultural belief & 0.4 & $0.2-0.9$ & 0.02 \\
\hline \multicolumn{4}{|l|}{$\begin{array}{l}\text { Preference of planned caesarean } \\
\text { section versus vaginal delivery }\end{array}$} \\
\hline Prefer planned caesarean section & - & & \\
\hline Prefer Spontaneous vaginal delivery & 7.3 & $3.7-14.4$ & 0.0001 \\
\hline \multicolumn{4}{|l|}{$\begin{array}{l}\text { Study site: Currently attending Antenatal } \\
\text { clinic in a regional versus district hospital }\end{array}$} \\
\hline Regional (Upper West regional hospital, Wa) & 2.0 & $1.3-3.0$ & 0.002 \\
\hline District (St Joseph's hospital, Jirapa) & - & & \\
\hline \multicolumn{4}{|l|}{ History of a previous caesarean section } \\
\hline No previous caesarean section & 3.5 & $2.1-5.7$ & 0.0001 \\
\hline Had a previous caesarean section & - & & \\
\hline \multicolumn{4}{|l|}{ Preferred mode of delivery } \\
\hline Caesarean section & - & & \\
\hline Vaginal delivery & 3.7 & $1.8-7.8$ & 0.0004 \\
\hline
\end{tabular}


Table 6 Multivariate logistic regression of factors independently associated with poor perception of caesarean section among pregnant women attending antenatal clinic; adjusting for education status, age and religion

\begin{tabular}{|c|c|c|c|}
\hline Maternal characteristics & Crude Odds Ratio & 95\% Confidence interval & P-Value \\
\hline \multicolumn{4}{|l|}{$\begin{array}{l}\text { Willingness to undergo } \\
\mathrm{CS} \text { if the need be }\end{array}$} \\
\hline Yes & - & & \\
\hline No or undecided & 3.8 & $2.0-7.3$ & 0.001 \\
\hline \multicolumn{4}{|l|}{$\begin{array}{l}\text { Is there any facility you would } \\
\text { avoid for child delivery }\end{array}$} \\
\hline No & - & & \\
\hline Yes & 0.4 & $0.2-0.8$ & 0.005 \\
\hline \multicolumn{4}{|l|}{$\begin{array}{l}\text { Preference of planned caesarean } \\
\text { section versus vaginal delivery }\end{array}$} \\
\hline Prefer planned caesarean section & - & & \\
\hline Prefer Spontaneous vaginal delivery & 6.3 & $3.0-13.4$ & 0.001 \\
\hline \multicolumn{4}{|l|}{$\begin{array}{l}\text { Study site: Currently attending Antenatal } \\
\text { clinic in a regional versus district hospital }\end{array}$} \\
\hline Regional (Upper West regional hospital, Wa) & 3.0 & $1.7-5.2$ & 0.000 \\
\hline District (St Joseph's hospital, Jirapa) & - & & \\
\hline \multicolumn{4}{|l|}{ History of a previous caesarean section } \\
\hline No previous caesarean section & 2.4 & $1.4-4.1$ & 0.001 \\
\hline Had a previous caesarean section & - & & \\
\hline \multicolumn{4}{|l|}{ Preferred mode of delivery } \\
\hline Caesarean section & - & & \\
\hline Vaginal delivery & 3.0 & $1.3-6.7$ & 0.007 \\
\hline
\end{tabular}

of pregnancies and children compared with the regional hospital for the same comparative maternal age. Since the proportion of CS increases with the number of pregnancies, the observed higher proportion of CS among those in the district hospital can be attributed to the differential number of births or pregnancies between the two groups.

Majority of the women preferred spontaneous vaginal delivery to caesarean section though a small proportion of women preferred caesarean section to spontaneous vaginal delivery. This is not an unexpected finding and is similar to a study in Ghana which found that $55 \%$ of pregnant women indicated similar preference [26]. Other studies in Ghana found 93.3\% [27] and 94\% [28] and a study from Nigeria [20] reported $85.7 \%$. This preference for vaginal delivery has been described as a reflection of the desire to have a natural birthing process rather than an aversion for CS [27], an attitude also portrayed by midwives and obstetricians in Sweden, a developed country with low CS rates [29]. There is worldwide deliberation about the significance of CS performed without medical indication [24, 25]. However, in this part of the world, maternal request due to non-medical indication seems to be of low priority. The limited access to health facilities with the capacity to conduct major surgeries, coupled with increased workload on the few trained health professional with the requisite skill, makes maternal request for caesarean section a difficult request to satisfy [30]. Also, traditional and cultural practices that discourage operative delivery, most likely contribute to the low number of CS for non-medical reasons $[19,31]$. However, contrary to the current findings, a recent report indicates that CS without medical indication is gaining ground in some centres in Africa [30].

Respondents generally had inadequate knowledge about CS, a finding which has been attested in other studies $[20,28]$. This is contrary to a study from Nigeria which found good knowledge among respondents [19]. The indications for CS were also not well known. This is similar to findings from a study in Cape Coast, Ghana, which found that only $45 \%$ of respondents knew at least one indication of CS [28]. Also, a substantial proportion of respondents believed that CS can have adverse effects on child survival and does not promote child survival. Almost half (45.1\%), consisting mostly of those who had never had a CS, did not know or feel that CS can promote child survival and one fifth of them (21.6\%) believed that CS can have adverse effects on child survival. This is similar to the findings of other studies [19, 27]. Over half of the respondents did not seem to be aware of indications for CS that prevent foetal compromise such as foetal distress and abnormal lie. Thus educative messages on CS should emphasise its role in protecting the foetus. 
Table 7 Factors associated with pregnancy loss/ perinatal mortality among women attending ANC

\begin{tabular}{|c|c|c|c|}
\hline Maternal characteristics & Adjusted Odds Ratio & 95\% Confidence interval & $P$-Value \\
\hline \multicolumn{4}{|l|}{ Age of Pregnant woman in years } \\
\hline 19 and below & - & & \\
\hline $20-24$ & 2.7 & $1.0-7.7$ & 0.05 \\
\hline $25-29$ & 3.2 & $1.2-8.8$ & 0.02 \\
\hline $30-34$ & 5.1 & $1.8-14.4$ & $<0.005$ \\
\hline 35 and above & 5.3 & $1.9-15.9$ & $<0.005$ \\
\hline \multicolumn{4}{|l|}{ Number of times pregnant (gravidity) } \\
\hline Two and below & - & & \\
\hline Three & 8.4 & $4.3-16.3$ & $<0.001$ \\
\hline Four & 14.3 & $7.2-28.3$ & $<0.001$ \\
\hline Five and above & 15.7 & $6.8-36.4$ & $<0.001$ \\
\hline \multicolumn{4}{|l|}{ Number of children (Parity) } \\
\hline Zero - one & - & & \\
\hline Two and above & 1.9 & $1.2-3.0$ & 0.005 \\
\hline \multicolumn{4}{|l|}{ History of previous caesarean section } \\
\hline \multicolumn{4}{|l|}{ No previous caesarean section } \\
\hline Positive history of previous caesarean section & 4.6 & $2.7-7.8$ & $<0.001$ \\
\hline \multicolumn{4}{|l|}{$\begin{array}{l}\text { Having traditional or cultural belief } \\
\text { against having caesarean section }\end{array}$} \\
\hline No traditional or cultural belief & - & & \\
\hline Have a traditional or cultural belief & 3.2 & $1.3-7.9$ & 0.01 \\
\hline \multicolumn{4}{|l|}{$\begin{array}{l}\text { Preference of planned caesarean } \\
\text { section versus vaginal delivery }\end{array}$} \\
\hline Prefer planned caesarean section & - & & \\
\hline Prefer Spontaneous vaginal delivery & 0.4 & $0.2-0.8$ & 0.005 \\
\hline \multicolumn{4}{|l|}{$\begin{array}{l}\text { Study site: Currently attending Antenatal } \\
\text { clinic in a regional versus district hospital }\end{array}$} \\
\hline Regional (Upper West regional hospital, Wa) & - & & \\
\hline District (St Joseph's hospital, Jirapa) & 0.4 & $0.2-0.6$ & $<0.001$ \\
\hline \multicolumn{4}{|l|}{$\begin{array}{l}\text { Form of anaesthesia used in the } \\
\text { previous caesarean section }\end{array}$} \\
\hline Spinal Anaesthesia & - & & \\
\hline General Anaesthesia & 0.2 & $0.05-0.9$ & 0.04 \\
\hline
\end{tabular}

As expected, the mothers who had had a previous CS seemed generally more knowledgeable and well informed about CS than those with no prior CS experience $[19,28]$. However, women in this study indicated that they had had several unanswered questions prior to the surgical procedure and if these had been addressed by health professionals before the surgery, it would have improved the CS experience. This suggests inadequate counselling prior to caesarean section among study the participants. Deliberate efforts should be made to educate pregnant women on CS and these efforts can be supported by the use of leaflets, posters, DVD's and case studies of mother who have had previous CS [28]. This can be delivered by a special counselling team of dedicated midwives as is done in Sweden to allay the fears of women [29]. It can also be a part of the general education given at school on childbirth as studies have also found that the level of knowledge about CS is influenced by one's level of education $[19,28]$, though others did not find a positive association [32]. A positive finding from this study is that the majority of respondents believed that adequate counselling and education during antenatal care might prepare women adequately for CS and are likely to increase the chances of success [27].

The majority of women were willing to have caesarean section if only if the need arose which is similar to findings in other more urban parts of the country and Nigeria $[19,27,28]$. Some women however would not 
undergo CS for any reason. This finding is similar to findings from a community-based study in the Upper West Region and one from Burkina Faso [33] and studies from Nigeria and Ghana which reported fear of death and pain as the main dangers $[19,20]$. The Upper West Region shares a border with Burkina Faso, and the regional hospital has reported cases of maternal mortality from Burkina Faso so it is not surprising that these studies have similar findings [25, 33]. Long recovery time is important in these environments since many of the rural women are poor subsistence farmers with several domestic roles. Therefore, the perception that CS weakens women, thereby limiting their physical capacity to farm, carry water or do other work, and restricts their ability to generate income for their families, may make them want to avoid institutional delivery $[21,25]$. This delay may be aggravated by the lack of transport facilities and poor roads which are prevalent in the region and which most likely contribute to high maternal deaths in the region $[34,35]$.

Several other reasons for not wanting a CS were identified in this study. Some of them are fear of pain, fear of complications, CS not being a natural procedure, fear of being mocked and the avoidance of a scar reported among others. These findings are similar to reports from other studies $[19,33]$. These fears may prevent women from delivering in hospitals when they perceive a higher chance of CS and they may delay presentation for emergency obstetric care required at the individual maternal level to prevent perinatal and neonatal mortality [30]. Thus measures to improve the uptake of emergency obstetric care must give consideration to how to address these fears and socio-economic factors surrounding CS during the recovery period $[21,25,33]$.

This study has some limitations. All participants in the study were from the Upper West Region and as such the findings may not be representative of the entire country, Ghana. There were variations with respect to the location and characteristics of the attendants to the facilities. Also being hospital-based study, the findings from the study may not entirely reflect the perceptions of those who deliver at home or in primary care facilities.

\section{Conclusion}

The majority of the respondents preferred vaginal delivery in this study and the reasons provided centred on long recovery time from CS, fears, attitudes, values, traditional and cultural beliefs. Though respondents generally had inadequate knowledge about CS, they had a positive attitude towards the uptake of CS. However, almost half of women did not know or feel that CS can promote child survival. This needs to be addressed through education to improve the perception of CS as a promoter of child survival and to discourage the notion that it causes adverse perinatal or neonatal outcome, particularly in at risk populations. It requires deliberate effort by midwives to present CS as an option for childbirth and improved neonatal survival which can be incorporated into general education on childbirth at antenatal clinics, in schools as well as public education. Additional effort should be made to reduce the recovery time and provide support systems for those who have a CS in this setting; otherwise the negative perceptions are likely to persist.

\section{Supplementary information}

Supplementary information accompanies this paper at https://doi.org/10. 1186/s12884-019-2536-8.

Additional file 1. Questionnaire, maternal perceptions about caesarean section \& neonatal health questionnaire.

\section{Abbreviations}

ANC: Antenatal Clinic; CS: Caesarean Section; NICU: Neonatal Intensive Care Unit; SDG: Sustainable Development Goal; UWRH: Upper West Regional Hospital; VBAC: Vaginal Birth after Caesarean Section

\section{Acknowledgements}

We acknowledge the significant contribution of Jerry Quaye and Lucy Sarfo in the collection of data for this study. We also thank all mothers who participated in the study.

\section{Authors' contributions}

EMAT, BBNG, DA, EA, NAHS and HBK participated in the design of the study. EMAT BBNG, BDN, DA, JY and EA supervised the data collection. BDN, BBNG, $J Y$ and EMAT conducted the analysis, interpretation and writing of the manuscript. All authors read through the manuscript and made significant contributions. All authors read and approved the final manuscript.

\section{Funding}

We are grateful to Global Affairs Canada, which funded this project under the Technology for Maternal and Child Health Project implemented by Savanna Signatures, Tamale, Ghana.

The analysis, interpretation of data and writing of the manuscript was funded by the authors.

\section{Availability of data and materials}

The datasets used and/or analyzed during the current study are available from the corresponding author on reasonable request.

\section{Ethics approval and consent to participate}

Permission to carry out this research was obtained from the Medical Directors of the Regional Hospital and St Joseph's District Hospital. Ethical Approval was obtained from the Ghana Health Service Ethical Review Committee (GHS-ERC: 09/03/17). Written informed consent was obtained from each study participant before the administration of questionnaires. Assent was obtained from all participants less than 16 years and consent obtained from their legal guardian/parent. In carrying out the interviews, privacy and confidentiality were ensured. Participation was based entirely on goodwill and there was no compensation for participating in this study.

\section{Consent for publication}

Not applicable

\section{Competing interests}

The authors declare that they have no competing interests.

\section{Author details}

${ }^{1}$ School of Medical Science, University for Development Studies, Tamale, Ghana. ${ }^{2}$ Upper West Regional Hospital, Wa, Ghana. ${ }^{3}$ Community Health Department, School of Public Health, University of Ghana, Accra, Ghana. 
${ }^{4}$ Public Health Department, Tamale Teaching Hospital, Tamale, Ghana.

${ }^{5}$ Shai-Osudoku District Hospital, Dodowa, Ghana.

Received: 31 May 2019 Accepted: 25 September 2019

Published online: 11 October 2019

\section{References}

1. Liu L, Johnson HL, Cousens S, Perin J, Scott S, Lawn JE, et al. Global, regional, and national causes of child mortality: an updated systematic analysis for 2010 with time trends since 2000. Lancet. 2012;379:2151-61. https://doi.org/10.1016/S0140-6736(12)60560-1.

2. McClure EM, Saleem S, Goudar SS, Moore JL, Garces A, Esamai F, et al. Stillbirth rates in low-middle income countries 2010-2013: a populationbased, multi-country study from the Global Network. Reprod Health. 2015, 12:S7. https://doi.org/10.1186/1742-4755-12-S2-S7.

3. GSS, GHS, ICF. Ghana maternal health survey 2017: key findings. Accra; 2018. https://www.dhsprogram.com/publications/publication-SR251-SummaryReports-Key-Findings.cfm

4. Gomez PP, Nelson AR, Asiedu A, Addo E, Agbodza D, Allen C, et al. Accelerating newborn survival in Ghana through a low-dose, highfrequency health worker training approach: a cluster randomized trial. BMC Pregnancy Childbirth. 2018;18:72. https://doi.org/10.1186/s12884-018-1705-5.

5. United Nations Children's Fund - UNICEF, World Health Organization - WHO, World Bank, Population Division UN-DESA. Levels and trends in child mortality. Report 2013. Estimates Developed by the UN Inter-agency Group for Child Mortality Estimation. 2013;34. https://www.popline.org/node/6491 03. Accessed 17 Apr 2019.

6. You D, Hug L, Ejdemyr S, Idele P, Hogan D, Mathers C, et al. Global, regional, and national levels and trends in under-5 mortality between 1990 and 2015, with scenario-based projections to 2030: a systematic analysis by the un inter-Agency Group for Child Mortality Estimation. Lancet. 2015;386: 2275-86. https://doi.org/10.1016/S0140-6736(15)00120-8.

7. Chou D, Daelmans B, Jolivet RR, Kinney M, Say L. Ending preventable maternal and newborn mortality and stillbirths. BMJ. 2015;351:19-22. https://doi.org/10.1136/bmi.h4255.

8. Flenady V, Wojcieszek AM, Middleton P, Ellwood D, Erwich JJ, Coory M, et al. Stillbirths: recall to action in high-income countries. Lancet. 2016;387:691702. https://doi.org/10.1016/S0140-6736(15)01020-X.

9. Bhutta ZA, Das JK, Bahl R, Lawn JE, Salam RA, Paul VK, et al. Can available interventions end preventable deaths in mothers, newborn babies, and stillbirths, and at what cost? Lancet. 2014;384:347-70 internal-pdf://0.0.2.84/ S0140673614607923.html.

10. Goudar SS, Goco N, Somannavar MS, Vernekar SS, Mallapur AA, Moore JL, et al. Institutional deliveries and perinatal and neonatal mortality in southern and Central India. Reprod Health. 2015;12:S13. https//doi.org/10.1186/1742-4755-12-S2-S13.

11. Mock CN, Donkor P, Gawande A, Jamison DT, Kruk ME, Debas HT. Essential surgery: key messages from disease control priorities, 3rd edition. Lancet. 2015;385:2209-19. https://doi.org/10.1016/S0140-6736(15)60091-5.

12. Betrán AP, Ye J, Moller A-B, Zhang J, Gülmezoglu AM, Torloni MR. The increasing trend in caesarean section rates: global, regional and national estimates: 19902014. PLoS One. 2016;11:e0148343 internal-pdf//0.0.2.75/article.html.

13. Betran AP, Torloni MR, Zhang JJ, Gülmezoglu AM. WHO Statement on Caesarean Section Rates. BJOG An Int J Obstet Gynaecol. 123:667-70. https://doi.org/10.1111/1471-0528.13526.

14. Temmerman M. Caesarean section surgical techniques: all equally safe. Lancet. 2016:388:8-9 internal-pdf://0.0.2.66/fulltext.html.

15. Ye J, Zhang J, Mikolajczyk R, Torloni MR, Gülmezoglu AM, Betran AP. Association between rates of caesarean section and maternal and neonatal mortality in the 21st century: a worldwide population-based ecological study with longitudinal data. BJOG An Int J Obstet Gynaecol. 123:745-53. https://doi.org/10.1111/1471-0528.13592.

16. Molina G, Weiser TG, Lipsitz SR, Esquivel MM, Uribe-Leitz T, Azad T, et al. Relationship between cesarean delivery rate and maternal and neonatal mortality. JAMA. 2015;314:2263-70. https://doi.org/10.1001/jama.2015.15553.

17. Boatin AA, Schlotheuber A, Betran AP, Moller A-B, Barros AJD, Boerma T, et al. Within country inequalities in caesarean section rates: observational study of 72 low and middle income countries. BMJ. 2018;360:1.

18. Kwawukume E. Caesarean section in developing countries. Best Pract Res Clin Obstet Gynaecol. 2001;15:165-78 https://www.sciencedirect.com/ science/article/pii/S152169340090155X. Accessed 18 Apr 2019.
19. Aziken M, Omo-Aghoja L, Okonofua F. Perceptions and attitudes of pregnant women towards caesarean section in urban Nigeria. Acta Obstet Gynecol Scand. 2007;86:42-7. https://doi.org/10.1080/00016340600994950.

20. Faremi A, Ibitoye O, Olatubi I, Koledoye P, Ogbeye G. Attitude of pregnant women in south western Nigeria towards caesarean section as a method of birth. Int J Reprod Contracept Obs Gynecol. 2014;3:709-14.

21. Filippi V, Ganaba R, Calvert C, Murray SF, Storeng KT. After surgery: the effects of life-saving caesarean sections in Burkina Faso. BMC Pregnancy Childbirth. 2015;15:348. https://doi.org/10.1186/s12884-015-0778-7.

22. Awoyinka BS, Ayinde OA, Omigbodun AO. Acceptability of caesarean delivery to antenatal patients in a tertiary health facility in south-West Nigeria. J Obstet Gynaecol (Lahore). 2006;26:208-10. https://doi.org/10.1080/ 01443610500508311

23. Rishworth A, Bisung E, Luginaah I. "It's Like a Disease": Women's perceptions of caesarean sections in Ghana's Upper West Region. Women Birth. 2016;29: e119-25 internal-pdf://0.0.2.79/Rishworth et al. - 2016 - "It's Like a Disease" Women's perceptions of caes.

24. Betran AP, Torloni MR, Zhang J, Ye J, Mikolajczyk R, Deneux-Tharaux C, et al. What is the optimal rate of caesarean section at population level? A systematic review of ecologic studies. Reprod Health. 2015;12:57. https://doi. org/10.1186/s12978-015-0043-6.

25. Souza JP, Gülmezoglu AM, Lumbiganon P, Laopaiboon M, Carroli G, Fawole $B$, et al. Caesarean section without medical indications is associated with an increased risk of adverse short-term maternal outcomes: the 2004-2008 WHO global survey on maternal and perinatal health. BMC Med. 2010;8:71. https://doi.org/10.1186/1741-7015-8-71.

26. Danso K, Schwandt H, ... CT-G medical, 2009 undefined. Preference of Ghanaian women for vaginal or caesarean delivery postpartum. ncbi.nlm. nih.gov. https://www.ncbi.nlm.nih.gov/pmc/articles/PMC2709173/. Accessed 18 Apr 2019.

27. Adageba R, Danso K, ... AA-D-G medical, 2008 undefined. Awareness and perceptions of and attitudes towards caesarean delivery among antenatal. ncbi.nlm.nih.gov. https://www.ncbi.nlm.nih.gov/pmc/articles/PMC2673831/. Accessed 18 Apr 2019

28. Prah J, Kudom A, Lasim O, Abu E. Knowledge, attitude and perceptions of pregnant women towards caesarean section among antenatal clinic attendants in Cape Coast, Ghana. Texila Int J Public Health. 2017;5.

29. Panda S, Daly D, Begley C, Karlström A, Larsson B, Bäck L, et al. Factors influencing decision-making for caesarean section in Sweden - a qualitative study. BMC Pregnancy Childbirth. 2018;18.

30. Harrison MS, Goldenberg RL. Cesarean section in sub-Saharan Africa. Matern Health Neonatol Perinatol. 2016;2:6. https://doi.org/10.1186/s40748-016-0033-x.

31. Sumankuuro J, Crockett J, Wang S. Maternal health care initiatives: causes of morbidities and mortalities in two rural districts of upper west region, Ghana. PLoS One. 2017;12:e0183644. https:/doi.org/10.1371/journal.pone.0183644.

32. Aali B, Motamedi B. Women's knowledge and attitude towards modes of delivery in Kerman, Islamic Republic of Iran. 2005. https://apps.who.int/iris/ handle/10665/116992. Accessed 19 Apr 2019.

33. Richard F, Zongo S, women's FO-I journal of, 2014 undefined. Fear, guilt, and debt: an exploration of women's experience and perception of cesarean birth in Burkina Faso, West Africa. ncbi.nIm.nih.gov. https://www. ncbi.nlm.nih.gov/pmc/articles/PMC4018416/. Accessed 19 Apr 2019.

34. Galaa S, Haruna U, Studies GD-GJ of D, 2016 undefined. Trends and Causes of Maternal Mortality at the Wa Regional Hospital, Ghana: 2005-2010. ajol.info. https J/ www.ajol.info/index.php/gjds/article/view/134657. Accessed 19 Apr 2019.

35. Sumankuuro J, Crockett J, open SW-B, 2018 undefined. Perceived barriers to maternal and newborn health services delivery: a qualitative study of health workers and community members in low and middle-income bmjopen. bmj.com. https://bmjopen.bmj.com/content/8/11/e021223.abstract. Accessed 19 Apr 2019

\section{Publisher's Note}

Springer Nature remains neutral with regard to jurisdictional claims in published maps and institutional affiliations. 